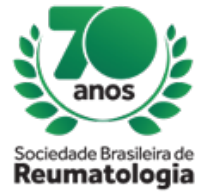

\title{
CYTOKINES LEVELS IN SYSTEMIC LUPUS ERYTHEMATOSUS BEFORE E AFTER ACUTE EXERCISE
}

Rosane Gouveia Vilela Machado (Universidade Federal de Jataí, Jataí, GO, Brasil), Heloisa Gouveia Machado (Universidade Federal de Goiás, Goiânia , GO, Brasil), Claúdio André Barbosa Lira (Universidade Federal de Goiás, Goiânia, GO, Brasil), Ludimila Paula Vaz Cardoso (Universidade Federal de Jataí, Jataí, GO, Brasil), Michelle Rocha Parise (Universidade Federal de Jataí, Jataí, GO, Brasil), Ricardo Borges Viana (Universidade Federal de Goiás, Goiânia, GO, Brasil), Jozelia Rêgo (Universidade Federal de Goiás, Goiânia, GO, Brasil), Ana Carolina Oliveira Silva Montandon (Universidade Federal de Goiás, Goiânia, GO, Brasil), Glayson Moura Gomes (Pontifícia Universidade Católica de Goiás, Goiânia, GO, Brasil), Monatha Nayara Guimarães Teófilo (Pontifícia Universidade Católica de Goiás, Goiânia, GO, Brasil), Vitalina de Souza Barbosa (Universidade Federal de Goiás, Goiânia, GO, Brasil), Nílzio Antônio da Silva (Universidade Federal de Goiás, Goiânia, GO, Brasil)

\section{BACKGROUND}

Physical exercise improves physical ability, muscle function, and various clinical symptoms, and may enhance the immune response in systemic lupus erythematosus (SLE). The effect of exercise on cytokine levels in SLE has been under evaluated. The aim of this study was to determine IL-6, IL-10, IL17A, TNF- $\alpha$ and IFN- $\alpha$ serum levels in patients with active and inactive SLE before and after acute exercise.

\section{MATERIALS AND METHODS}

This study included 31 female patients with SLE being 11 patients with active SLE and 20 patients with inactive SLE. The serum samples were obtained from the participants before and soon after the maximal stress test. Specific kits were used for determination of serum cytokines, IL-6, IL-10, IL-17A, TNF- $\alpha$ and interferon- $\alpha$ by ELISA method (human IL- 6 and TNF- $\alpha$ ELISA, Invitrogen ${ }^{\circledR}$, human IL-10 and IL-17A Platinum ELISA, eBioscienceTM, and IFN- $\alpha$ ELISA, VeriKineTM). The data are presented as mean and standard deviation, Mann-Whitney test was used for variables with non-normal distribution and Exact Fisher test was used to compare categorical variables. To compare IL-6, IL-10, IL-17A, TNF- $\alpha$ and IFN- $\alpha$ levels between groups, the GEE (Generalized Equations Estimating) method was used. It was considered statistically significant a $p$ value $\leq 0.05$.

\section{RESULTS}

As for the characteristics of active and inactive SLE, there was no significant difference regarding to the age $(35.61 \pm 2.19$ years vs. $33.45 \pm 1.37$ years; $p=0.353)$, body mass index $(23.16 \pm 1.21 \mathrm{Kg} / \mathrm{m} 2 \mathrm{vs}$. $23.62 \pm 0.81$ $\mathrm{Kg} / \mathrm{m} 2 ; \mathrm{p}=0.726)$ and disease duration (120.46 \pm 34.01 months vs. $114.35 \pm 17,14$ months; $\mathrm{p}=0.901)$. There was no difference in the levels of IL-6, IL-10, IL-17A, TNF- $\alpha$ and IFN- $\alpha$ when we compared: active SLE before and after acute exercise $(p=1.0 ; p=0.354 ; p=0.356 ; p=0.356 ; p=0.356$ respectively); inactive SLE before and after acute exercise $(p=-0.398 ; p=0.303 ; p=0.089 ; p=0.089 ; p=0.089$ respectively) and between active and inactive SLE after acute exercise ( $p=0.305 ; p=0.969 ; p=0.855 ; p=0.855 ; p=0.855$ respectively).

\section{CONCLUSION}

We did not observe change on the levels of cytokines soon after acute exercise in active and inactive SLE. In order to detect changes in cytokine level, might be necessary to quantify the cytokines at different times after the acute exercise and it may be relevant to consider intensity and duration of the acute exercise. 